\title{
UM SIMULADOR EDUCACIONAL PARA DISCIPLINA DE FÍSICA EM MUNDOS VIRTUAIS
}

\author{
Luciano Kercher Greis - PPGEDU - UFRGS - lucianokgsl@gmail.com \\ Eliseo Reategui - PPGEDU/PPGIE - UFRGS - eliseoreategui@gmail.com
}

\begin{abstract}
Resumo: Uma nova geração de alunos, imersos em tecnologias que envolvem a utilização de mensagens de texto, mídias sociais e games vem surgindo a cada dia, trazendo um foco diferente, uma mentalidade e um estilo de aprendizagem distinto em relação às gerações que os precederam. Estes alunos sentem-se igualmente confortáveis aprendendo em ambientes virtuais ou reais, pois não conseguem ver a diferença que separa um mundo do outro. Este artigo apresenta a possibilidade de utilização de um simulador social como recurso pedagógico, apresentando o recurso de simulação educativa de um conteúdo da disciplina de física no contexto de um mundo virtual. Podemos trazer para esta situação de ensino/aprendizagem a possibilidade de reproduzir experiências pessoais, que são certamente mais intensas e significativas do que situações em que apenas apresentamos um modelo descritivo demonstrando o fenômeno. Novas possibilidades de interação e colaboração surgem neste modelo de simulação.
\end{abstract}

Palavras-chave: mundos virtuais, second life, simulador educacional, simulador social, colaboração, interação, interatividade

\section{AN EDUCATIONAL SIMULATOR FOR DISCIPLINE OF PHYSICS IN VIRTUAL WORLDS}

\begin{abstract}
A new generation of students, immersed in technologies that involve the use of text messaging, social media and games, increase everyday, bringing a different focus and mentality, and a different learning style comparing with preceeding generations. These students feel comfortable to learn in virtual or real environments, as they cannot see the differences that separate one world from the other. This article presents the possibility of using a social simulator as a pedagogical resource, presenting an educational simulation of a physics course in the context of a virtual world. We can bring to this teaching/learning situation the possibility to reproduce personal experiences, which are certainly more intense and more meaningful than situations in which we would only present a descriptive model demonstrating physics phenomena. Novel interaction and collaboration possibilites rise in this simulation model.
\end{abstract}

Keywords: virtual worlds, second life, educational simulator, social simulation, collaboration, interactivity

\section{Introdução}

As dificuldades dos alunos quanto à aprendizagem na disciplina de Física já são bem conhecidas, principalmente quando falamos em estudantes do nível médio. A forma como as teorias são introduzidas em sala de aula, quando dissociadas da realidade e apresentadas essencialmente por um conjunto de fórmulas prontas e sem significado para o aluno, pode ser apontada como uma das maiores responsáveis pela relutância destes em relação a esta disciplina. Na busca por soluções, o computador passou a ser empregado como uma ferramenta no ensino/aprendizagem das ciências físicas (Fiolhais e Trindade, 2003). Recursos multimídia como hipertextos, imagens, animações e vídeos, representam algumas das 
alternativas possíveis para o processo de ensino e aprendizagem.

Podendo ser utilizados como ferramentas que auxiliam professores e alunos, estes recursos favorecem uma aproximação entre os conceitos teóricos e a realidade que observamos. A partir do interesse do aluno pela análise dos fenômenos físicos observáveis através de uma animação por exemplo, é possível inserir conceitos mais teóricos e utilizar a matemática como uma ferramenta para compreendê-los.

Os avanços na área de computação abriram pouco a pouco novas perspectivas para o professor abordar estes mesmos conteúdos. Uma nova possibilidade que foi tornando-se viável para o ensino da física são as simulações educacionais, as quais permitem reproduzir em sala de aula conceitos físicos que necessitariam de modelos mais complexos para compreensão dos fenômenos observáveis no mundo real.

Estas novas possibilidades sugerem novas formas de interação entre alunos e os conteúdos que estão sendo trabalhados de forma digital. Este diálogo que se estabelece entre o homem e a máquina, o qual chamamos de interação (Lemos, 2002), possibilita nas simulações educacionais um novo patamar de interatividade para o aluno, ou seja, uma maior ação ou controle sobre o ambiente que está sendo explorado.

A interatividade, que pode ser classificada de acordo com níveis pré-estabelecidos (Miller, 2004), indica a potencialidade de o aparato permitir a interação entre o homem e a máquina, ou a possibilidade de o usuário exercer no ambiente uma influência sobre seu conteúdo e a forma como a comunicação esta sendo mediada (Jensen, 1998). Através de uma ação interativa direta sobre elementos do ambiente, podemos alterar valores de variáveis que foram inicialmente previstas por aquele conjunto de alternativas, agindo diretamente sobre a informação dada e alcançando diferentes resultados. Já para Piaget (1978), o conceito de interação considera a relação entre indivíduos e os processos complexos de trocas e significações.

Do ponto de vista da interatividade, avançamos ainda mais quando consideramos os SIMS ou Mundos Virtuais como ferramentas para o ensino/aprendizagem. Estes ambientes permitem uma representação virtual do usuário em um mundo artificialmente recriado, e trazem para este contexto elementos originários dos games e dos ambientes de simulação (Aldrich, 2009). Neste trabalho investigamos justamente algumas possibilidades pedagógicas para utilização de recursos de simulação de fenômenos físicos em Mundos Virtuais.

Este artigo apresenta um simulador educacional desenvolvido pra a disciplina de física, construído em um Mundo Virtual. O conteúdo abordado por este simulador é a colisão de dois corpos, no qual estão envolvidos os conceitos físicos de massa, velocidade e coeficiente de elasticidade. A ambientação deste fenômeno de colisão utiliza uma situação que pode ser encontrada no mundo real, a colisão de dois carros em uma montanha russa.

\section{A Simulação como instrumento educacional}

Para Kapp e O’Driscoll (2010), o termo simulação possui vários significados. O mais conhecido inclui a utilização de softwares que buscam emular equipamentos atuais para treinamento, como o que ocorre com o Fligth Simulator por exemplo, onde aprendizes pilotos aprendem a voar utilizando um ambiente realista. $\mathrm{O}$ sistema reproduz uma parte do ambiente real, o qual o aprendiz irá conhecer, aprender e praticar.

Outro tipo de simulador, classificado como Simulador Social, consiste de pessoas utilizando um sistema simulado para interagir com outras pessoas. Estes sistemas buscam incentivar as 
pessoas a aprender a interagir em um ambiente artificial. Simuladores sociais utilizam fotografias, vídeos ou mais recentemente, componentes tridimensionais. Segundo Kapp e O’Driscoll (2010), uma nova geração de aprendizes, imersos nestas tecnologias que envolvem a utilização de mensagens de texto, mídias sociais e vídeo-games, vem surgindo a cada dia. Estes novos alunos estão surgindo nos meios acadêmicos e nas próprias empresas, com um foco diferente, uma mentalidade e um estilo de aprendizagem distinto em relação às gerações que os precederam. Esta geração de alunos e trabalhadores não consegue ver a diferença que separa ambientes virtuais de físicos, sentem-se igualmente confortáveis aprendendo em ambos os mundos - real ou virtual.

Desta forma, torna-se importante delimitar aqui o sentido considerado para o termo simulação, não estando este restrito apenas a uma animação ou a uma navegação orientada através de um ambiente construído digitalmente. Está sim relacionado diretamente à possibilidade do usuário de interagir com os recursos de software e hardware oferecidos pela plataforma que esta sendo utilizada. Esta ação do usuário sobre o ambiente simulado interfere nos resultados observáveis. Também estamos considerando as trocas e significações entre os participantes, as possibilitadas propostas por esta mídia social, que instiga a colaboração e a interação entre alunos

Podemos através da simulação, imitar ou reproduzir situações reais ou mesmo propostas na forma abstrata, dos fenômenos que desejamos simular. Os experimentos que utilizam estas possibilidades buscam entender o comportamento ou avaliar estratégias para a sua operação. Aldrich (2009), delimita Simulações Educacionais como ambientes estruturados, abstraídos de alguma atividade da vida real, que permitem aos participantes praticar suas habilidades no mundo real, pois fornecem feedback apropriados em um ambiente cujos resultados são controlados e previsíveis.

As vantagens em se trabalhar com modelos simulados por computador no campo educacional são muitas. Desde a oportunidade de tornar possível a reprodução de processos muito lentos ou muito perigosos para serem reproduzidos no ambiente natural, passando pelo controle das etapas necessárias para a observação dos fenômenos e até mesmo pela redução dos custos envolvidos no projeto.

Simuladores de voo como o já citado Fligth Simulator ou ainda o Fligth Gear, trazem bons exemplos de utilização de simuladores já em operação. O realismo alcançado por estes softwares permite ampliar as horas de treinamento de pilotos, repassar procedimentos e situações que ocorrem durante todas as etapas do voo, reduzindo custos e o perigo que poderia apresentar este treinamento para pilotos. Através destes simuladores, pilotos podem por exemplo, treinar para agir em caso de pane da aeronave, uma situação que seria impossível de ser replicada fora de ambientes de simulação.

Também são utilizados simuladores de processos produtivos em indústrias ou mesmo nas áreas de saúde, medicina, arquitetura, engenharia entre outras. Nas escolas, aulas de química, física ou astronomia, possuem atividades que envolvem softwares de simulação, substituindo atividades que seriam inicialmente realizadas nos laboratórios da instituição.

Outro avanço na questão da interação com recursos computacionais surge com o vídeo-game, trazendo elementos de competição, fantasia, narrativa e mesmo uma preocupação com a navegação (usabilidade) e a estética do ambiente. Tais características podem ser contribuir na construção de ambientes de simulação mais envolventes e interativos, tornado-os ainda mais interessantes do ponto de vista educacional. 
Para Aldrich (2009), alguns elementos que encontramos nos jogos de vídeo-game podem favorecer a motivação, criando em modelos de software pedagógicos situações equivalentes as que encontramos nos modelos de jogos criados para entretenimento. Para o autor, aprender a partir de um jogo é mais natural do que em uma sala de aula tradicional. A motivação do aluno para aprender neste ambiente é maior, e parte das incertezas geradas pelos diversos níveis de dificuldade do jogo. Informações ocultas e desafios, o apelo emocional da fantasia criada pela história que envolve esta atividade e a curiosidade, são componentes cognitivos que fazem parte do contexto deste ambiente.

O universo de possibilidades para a simulação é ampliado a partir de meados da década de 2000 com o surgimento dos mundos virtuais. Reunindo características que encontramos em games, em simulação e utilizando tecnologias de realidade virtual, estes ambientes permitem a representação física do usuário em um espaço virtual recriado tridimensionalmente. Múltiplos utilizadores podem compartilhar o mesmo espaço simultaneamente, acessando-o através da internet de qualquer lugar do mundo, e utilizando sistemas de comunicação por voz ou chat presentes no próprio ambiente para interagir entre si. Objetos interativos construídos pelos próprios usuários dentro do mundo virtual podem ser compartilhados e utilizados simultaneamente.

\section{Os Mundos Virtuais}

SIMS ou Mundos Virtuais trazem novas possibilidades pedagógicas para o processo de ensino e aprendizagem. A partir de suas funcionalidades, podemos pensar na possibilidade de construção colaborativa de conteúdos, na distribuição de textos, sons, vídeos, hiperlinks, objetos simulados e interativos, na comunicação a distância por voz e chat, além da navegação intuitiva por cenários que são recriados do mundo real para um ambiente 3D interativo.

A comunicação síncrona ou mesmo assíncrona entre professores e alunos, aqui representados digitalmente por avatares, ou a representação física dos usuários neste ambiente, e que estão presentes simultaneamente em uma mesma sala de aula virtual, utilizando ferramentas de comunicação por voz disponibilizados pela interface do ambiente, já constitui um exemplo bastante interessante de utilização desta ferramenta no contexto educacional. Mas podemos ainda associá-lo a exibição de filmes, imagens, slides com conteúdos, links para páginas da internet que podem ser acessados de dentro do ambiente, além de objetos interativos, que podem ampliar a gama de recursos que este ambiente oferece.

Os mundos virtuais utilizam tecnologias que estão presente em ambientes de realidade virtual. Para Tori (2005) realidade virtual é definida como uma interface avançada do usuário, para acessar aplicações executadas no computador, tendo como características a visualização de, e movimentação em, ambientes tridimensionais em tempo real e a inserção com elementos desse ambiente.

O conceito de mundos virtuais pressupõe características de imersão, interação e navegação. Book (2004) caracteriza os mundos virtuais com os seguintes aspectos:

- Espaço partilhado: vários usuários congregados num mesmo espaço de tempo;

- Interface gráfica: existência de um ambiente virtual em 3 dimensões;

- Imediaticidade: interação ocorre em tempo real;

- Interatividade: possibilidade do usuário alterar e criar conteúdos; 
- Persistência: usuários continuam permanentes no mundo, mesmo estando o utilizador off-line;

- Socialização/Comunidade: formação de comunidades de interesse.

Atualmente podemos encontrar uma centena de ambientes que satisfazem as características necessárias para classificá-los como mundo virtual. Descrevemos aqui alguns destes ambientes:

- Second Life: o mais conhecido e famoso mundo virtual é também o que oferece o maior número de recursos de interação e personalização da interface. O acesso ao ambiente é gratuito, mas para a ocupação dos terrenos (espaços virtuais) são cobradas taxas de seus usuários. Também existe a possibilidade de acesso pago através de mensalidade, que fornece um subsídio financeiro dentro do ambiente para que você adquira bens ou terrenos virtuais. O sistema econômico é bastante completo, e os créditos podem ser adquiridos diretamente do criador do jogo, a Linden Lab, ou mesmo no mercado paralelo. Seus créditos no jogo também podem ser vendidos, o que resultou em um sistema comercial bastante interessante.

- Kaneva: apresenta uma boa qualidade de navegação além da qualidade das construções tridimensionais e dos avatares. Ao criar um registro neste ambiente, você adquire um espaço gratuito, podendo disponibilizar vídeos e áudios através de streaming.

- HIPIHI: Com interface muito semelhante ao Second Life, esta versão chinesa para mundos virtuais possui algumas limitações de acesso impostas pelo governo do país de origem. Também a língua utilizada no ambiente pode ser um impedimento para utilizar esta opção.

- Open Simulator: é uma versão disponibilizada em gratuitamente e em código aberto, desenvolvido à partir de antigos códigos de programação do Second Life. Praticamente todas as funcionalidades do SL possuem um equivalente neste mundo virtual, ficando como ponto negativo o fato de o ambiente ainda não ter atingido uma estabilidade no fornecimento de acesso a sua plataforma.

- Habbo Hotel: como o nome sugere, este que é um dos mais populares mundos virtuais está ambientado em um hotel. Os usuários, em sua grande maioria crianças de até 9 anos o utilizam para conversas através do chat e para a personalização de seus avatares através da compra de roupas e acessórios.

- Club Penguin: bastante semelhante ao Habbo Hotel, neste mundo virtual destinado a crianças todos os usuários tornam-se pingüins. O maior número de usuários registrados neste ambiente foi registrado ainda em 2007, ano em que foi adquirido pela empresa The Walt Disney Company.

- There.com: com uma interface bastante simples, este mundo virtual teve grande repercussão na mídia em meados de 2007. Porém o número de possibilidades de interação é limitado neste ambiente, quando comparados a outras possibilidades.

- Meez: a qualidade das construções e dos avatares disponíveis neste ambiente, aliado a possibilidade de inseri-lo como um plug-in em outros sites, como o Moodle por exemplo, tornam este ambiente bastante interessante. Mas entre os pontos negativos encontramos as limitadas opções de personalização dos ambientes e a impossibilidade 
de inserir objetos interativos.

- Home: destinado a servir de mídia social para jogadores on-line para Playstation3, este ambiente tem como característica principal a possibilidade de ser acessado diretamente pelo console da Sony.

Utilizaremos como referência neste artigo, o mundo virtual Second Life (SL), pois este ambiente disponibiliza um maior número de recursos técnicos em relação aos demais ambientes. O SL permite aos próprios usuários construir e distribuir objetos em qualquer formato físico, com interatividade programável através de scripts, além de oferecer todas as possibilidades técnicas já citadas anteriormente.

\section{Um simulador de física para o Second Life}

O ponto de partida e modelo que servirá de referência para a construção do sistema computacional desenvolvido nesta pesquisa, foi o simulador de física disponível para acesso online e apresentado na figura $1^{1}$.

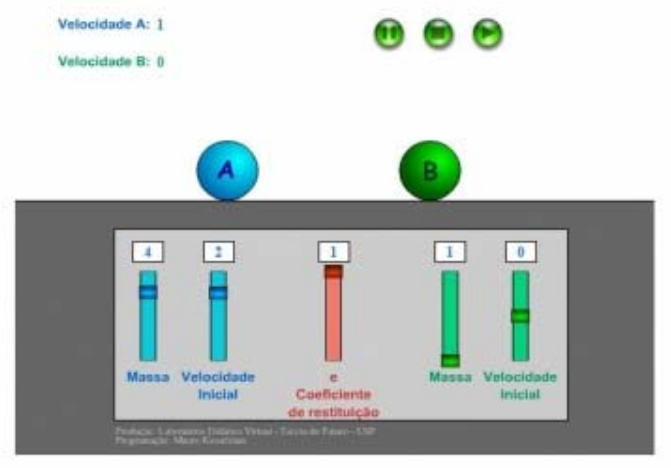

Figura 1: Modelo de simulação da colisão física

Destinado ao ensino e aprendizagem do fenômeno físico da colisão entre dois corpos "A" e "B", este modelo possibilita que um aluno defina os valores das variáveis envolvidas na simulação: velocidade inicial e massa de ambos os corpos, além do coeficiente de elasticidade. A simulação é apresentada através de uma interface simples, onde o aluno deve alterar as variáveis e pressionar o botão para iniciar a animação.

Ao reproduzir esta simulação em um mundo virtual, podemos ampliar as possibilidades de interação do usuário com o modelo simulado. A imersão do aluno no ambiente, através de seu avatar, assim como o cenário e objetos interativos construídos em três dimensões, e aliado às possibilidades de comunicação que a plataforma nos oferece, permite que novas situações de aprendizagem sejam planejadas para o mesmo conteúdo.

Para dissertar sobre a capacidade de utilização pedagógica dos mundos virtuais, procuramos reproduzir uma situação que não só ambientasse o fenômeno físico da colisão de dois corpos em algo possível de ser observado em uma situação real, mas que também contemplasse a imersão do aprendiz no modelo de simulação proposto. A situação escolhida foi o choque de dois veículos que se locomovem sobre trilhos, como por exemplo em uma montanha russa (figura 2).

\footnotetext{
${ }^{1}$ Acessado em:http://www.cienciamao.if.usp.br/tudo/exibir.php?midia=lab\&cod=_colisao
} 


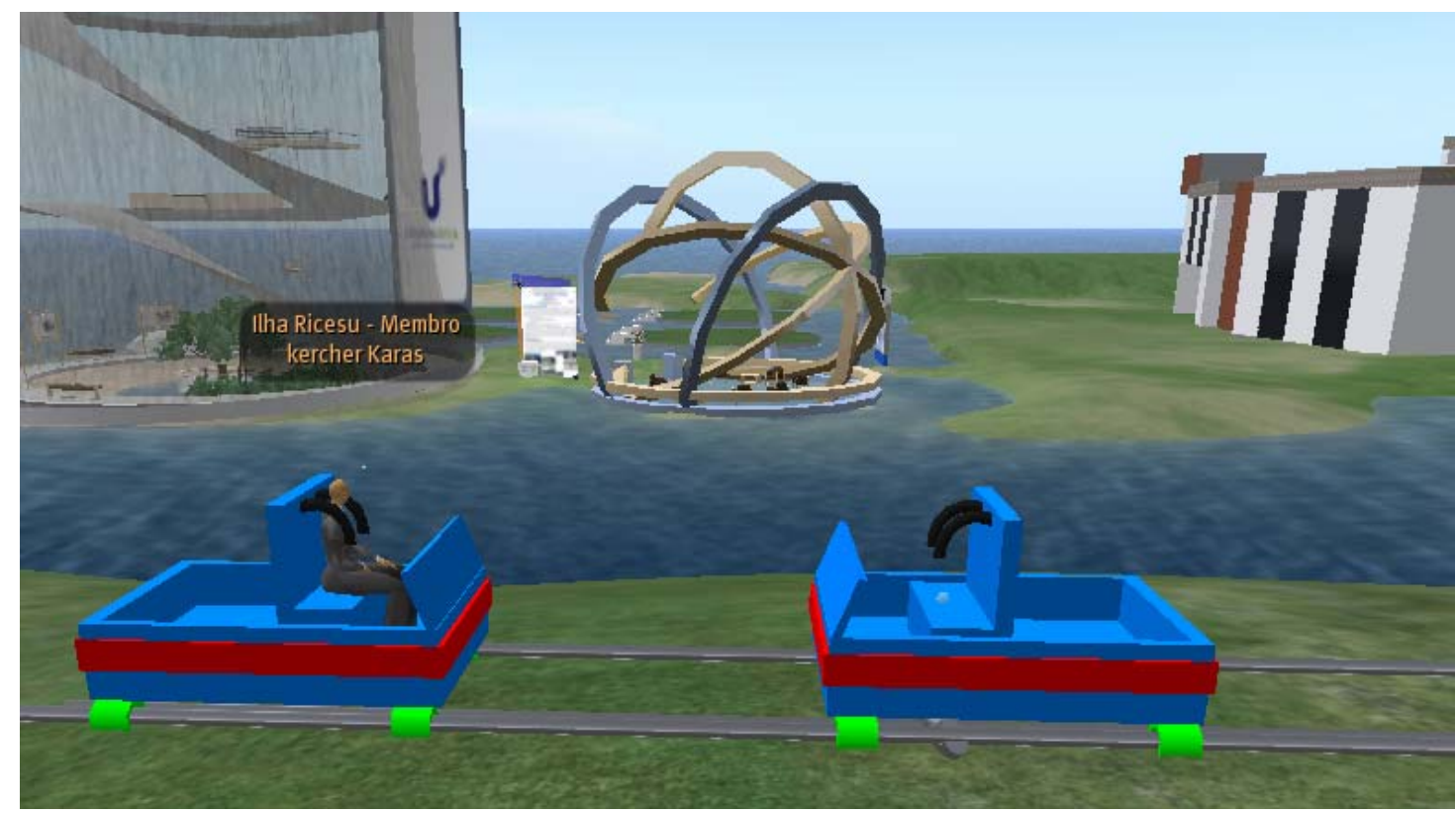

Figura 2: Modelo de simulação da colisão física desenvolvido nesta pesquisa

A narrativa escolhida possibilita remeter os estudantes a um parque de diversões, no qual alunos e professores se reúnem para visualizar uma situação de colisão real. A construção dos veículos envolvidos na simulação permite que os alunos estejam no interior dos corpos que irão colidir. Além da observação do fenômeno do interior do veículo, é possível que a colisão seja observada de diversos ângulos diferentes de fora do veículo, e repetidas vezes para a melhor compreensão do fenômeno físico.

Nesta simulação, um ou dois alunos podem participar diretamente da simulação, já que o sistema permite que ambos os objetos que irão colidir na simulação tenham suas variáveis definidas independentemente. Interessante observar que inserimos um componente de colaboração na atividade, visto que os alunos e professores envolvidos na simulação podem estar fisicamente distantes entre si, mas irão acionar a simulação em conjunto e observar o mesmo fenômeno simultaneamente.

Para acionar a simulação, os alunos devem estar posicionados no interior do veículo, selecionar as variáveis disponíveis através do painel de instrumentos e posteriormente acionar a simulação. Ambos os carrinhos se moverão de acordo com os valores indicados pelos alunos e irão colidir. A direção e velocidade final dos carrinhos serão calculados pelo sistema e resultarão na movimentação observável destes após o choque. É possível, assim como no sistema que serviu de referência para esta simulação, que os valores indicados pelos alunos não resultem em uma colisão, o que não é uma falha, mas uma possibilidade em função dos valores das variáveis indicadas.

Após esta colisão, o aluno pode acionar repetidas vezes o sistema para observar o fenômeno quantas vezes forem necessárias para sua compreensão, ou ainda realizar alterações nas variáveis e observar os novos resultados.

O sistema também contempla a possibilidade de que outros alunos, apesar de não acionarem diretamente o simulador, possam estar presentes como espectadores ou mesmo sentados em outros bancos disponíveis no interior do veículo. Em conjunto com as ferramentas de comunicação disponibilizadas pelo ambiente, isto permite que vários alunos possam participar de uma aula a distância por exemplo, utilizando este modelo de simulador. 
Disponibilizar outros componentes pedagógicos no ambiente também é um recurso permitido pelo ambiente e que pode enriquecer a experiência dos alunos nesta simulação. Vídeos com tutoriais, dicas ou orientações podem ser inseridos a partir de streaming de vídeo, como por exemplo o Youtube. Links para artigos ou sites publicados na internet podem ser acessados diretamente de dentro do ambiente, assim como a visualização de imagens em pôsteres e projetores de slides, recurso bastante semelhante a uma apresentação em PowerPoint no mundo real.

Arquivos de texto contendo informações podem ser criados com um editor de texto presente no próprio sistema, e disponibilizados entre os usuários de forma bastante simplificada. Os usuários podem criar grupos de amizade, divulgando informações e distribuindo conteúdos especificamente para este grupos. Enfim, o leque de opções disponíveis neste ambiente pode ser ainda mais ampliado quando integramos funcionalidades da internet na interface do ambiente.

\section{Discussão e Considerações Finais}

Este artigo apresentou um simulador educacional desenvolvido para a disciplina de física, construído em um mundo virtual.

A partir da comparação do modelo de simulação educacional inicialmente proposto, podemos observar que o emprego de mundos virtuais na implementação do sistema possibilitou um incremento de qualidade no objeto de aprendizagem desenvolvido. Esta possibilidade é resultante de vários fatores, como:

- nível mais elevado de interatividade proporcionado pelo ambiente virtual em três dimensões;

- desenvolvimento de uma narrativa mais complexa para a simulação, na qual o próprio estudante pode se encontrar na cena;

- refinamento da estética do cenário construído;

- diversificação das formas de apresentação do mesmo conteúdo de física (simulação, vídeo, diagramas e textos).

Como salienta Aldrich (2009), tais elementos influenciam o modo como os estudantes interagem com o objeto de estudo, enriquecendo as experiências de aprendizagem.

Quando utilizamos os recursos de tecnologia tridimensional, conseguimos reproduzir com qualidade os ambientes reais que serviram de modelo para a simulação que está sendo observada. Esta possibilidade de ambientar o fenômeno que está sendo estudado, trás para o processo de ensino/aprendizagem a capacidade de o aluno relacionar o conteúdo da simulação com experiências pessoais que ele já tenha vivenciado. Estas experiências pessoais são certamente mais intensas e significativas para ele do que o modelo descritivo que simplesmente demonstra o fenômeno, desencadeando no aluno um maior interesse e engajamento nas atividades propostas pela disciplina.

Outro fator que nos leva a identificar uma ampliação do engajamento do aluno nos modelos de simulação produzidos em mundos virtuais é através da imersão proporcionada pela representação virtual destes no ambiente. Os mecanismos de controle do personagem virtual, o avatar, possibilitam uma quase presença do aluno dentro da simulação que está sendo estudada. Este sentido de telepresença amplia a experiência do aluno na interação com o modelo de simulação e principalmente com os conteúdos que estão sendo trabalhados (Lévy, 
1996). Portanto, não apenas vemos a colisão, mas substancialmente fazemos parte dela.

Características de interação dos mundos virtuais também favorecem a construção de atividades colaborativas. Alunos e professores podem atuar simultaneamente sobre o mesmo objeto simulado, utilizando os mesmos mecanismos de manipulação sobre o ambiente. A atividade que propomos para este ambiente por exemplo, contempla a ação colaborativa para até dois alunos diretamente envolvidos. Mas podemos propor outros exemplos em que a atividade necessite de vários alunos envolvidos no mesmo modelo simulado para que o fenômeno seja observado.

O fato de estar utilizando uma mídia social, possibilita que pessoas de outros lugares, com outras culturas também compartilhem o mesmo ambiente simultaneamente. Isto oferece possibilidades de aprendizagem que seriam mais difíceis de ocorrer em outra situação.

Por fim, identificamos que estes ambientes favorecem a interatividade de alunos e professores envolvidos nos processos de simulação, auxiliando na compreensão dos conteúdos que estão sendo abordados. A imersão propiciada pelos avatares, pelas construções de cenários e objetos tridimensionais, além das relações sociais que se estabelecem nesta mídia social, pode ser o motor que instiga alunos a um engajamento e dedicação maiores neste espaço virtual. Para estes novos alunos, que não distinguem a diferença entre aprender em um ambiente real ou virtual, novos espaços de aprendizagem surgem a cada dia, e podem ser integrados aos processos de ensino/aprendizagem.

Certamente elementos que estão hoje presentes nos mundos virtuais apresentam qualidades que podem enriquecer as novas mídias que ainda estão por ser desenvolvidas. Assim como hoje buscamos integrar nos materiais educacionais componentes encontrados em recursos que sabidamente interessam os estudantes, como no caso dos games (Aldrich, 2009), também estamos construindo elementos que servirão de modelo para as novas mídias que estão por vir.

\section{Referências}

ALDRICH, CLARK (2009). Learning online with games, simulations and virtual worlds. San Francisco, CA, Jossey-Bass

ALDRICH, CLARK (2009). The complete guide to simulations and serious games. San Francisco, CA, Pfeiffer

FIOLHAIS, C., TRINDADE, J.(2003) Física no computador: o computador como uma ferramenta no ensino e na aprendizagem das ciências físicas. Revista Brasileira de Ensino de Física vol.25 no.3 São Paulo. Sept. 2003

JENSEN, Jens.(1998) Interactivity: Tracking a New Concept in Media and Communication Studies. Nordic Review

KAPP, KARL M.; O’DRISCOLL, tony (2010). Learning in 3D: adding a new dimension to enterprise learning and collaboration. San Francisco, CA, Pfeiffer

Lemos, A., Cibercultura (2002). Tecnologia e Vida Social na Cultura Contemporânea. Porto Alegre, Sulina

LÉVY, PIERRE. (1996) O Que é Virtual. São Paulo: Editora 34

MILLER, C. (2004) Digital storytelling: a creator`s guide to interactive entertainment. 
Burlington, MA: Focal Press,

PIAGET, J. Fazer e Compreender , São Paulo: EDUSP/Melhoramentos, 1978.

PRENSKY, M. (2001). Digital Natives, Digital Immigrants. On the Horizon, MCB University Press, v.9, n. 5, 2001. Disponível em: http://www.marcprensky.com/writing/Prensky\%20\%20Digital\%20Natives,\%20Digital\%20Immigrants\%20-\%20Part1.pdf>. Acesso em: 07 setembro. 2007.

TORI, ROMERO; KIRNER, CLÁUDIO; SISCOUTTO, ROBSON.(2006) Fundamentos e tecnologia de realidade virtual e aumentada. Belém: VIII Symposiun on Virtual Reality, 2006. disponível em: http://www.gamecultura.com.br/downloads/livros/livrosvr2006-final.pdf 